\author{
VERSITA 10.2478/v10310-012-0014-5 \\ Ovidius University Annals of Chemistry \\ Volume 23, Number 1, pp. 87-91, 2012
}

\title{
Characterization and stability study of some pharmaceutical ointments
}

\author{
Viorica POPESCU, Alina SOCEANU*, Simona DOBRINAS and Gabriela STANCIU
}

Department of Chemistry and Chemical Engineering, Ovidius University, 124 Mamaia, Constanta 900527, Romania

\begin{abstract}
In the present study we have determined some characteristics (aspect, odor, solubility, emulsion type, water and volatile substances content, total fatty matter, saponification index, ester index) for three pharmaceutical ointments belonging to the group of non-steroidal anti-inflammatory: Diclac, Ketonal, Indometacin and one antibiotic ointment for ophthalmic use: Ophtagram. In order to achieve stability study of studied ointments, the $\mathrm{pH}$, the acidity index, the peroxide index and the iodine index were determined over a year every three months. After 9 months from the opening of the tubes, analytical determinations have shown that $\mathrm{pH}$ values, acidity, peroxide and iodine indexes no longer fit to the values recommended for medical use, which confirms the directions available on the package.
\end{abstract}

Keywords: ointments, characteristics, stability study

\section{Introduction}

Ointments are used topically as protectants, antiseptics, emollients, antipruritics, kerotolytics and astringents. The ointment base is very important, as it determines the use of the ointment. Ointment bases are divided into five types and they are oleaginous bases, absorption bases, water-in-oil emulsion bases, oil-in-water emulsion bases and water-miscible bases. Each type of the ointment bases has its unique physical characteristics [1-3].

Diclac belong to the group of medicines called anti-inflammatory drugs, which are used to reduce inflammation and pain in the joints and muscles. The active ingredient is diclofenac sodium and other ingredients are isopropyl alcohol, macrogol hump-7glycerol, hypromellose, perfume, purified water.

Ketonal is a non-steroidal antirheumatic drug belonging to the propionic acid derivatives group. Has a strong analgesic activity, anti-inflammatory and antipyretic. Ketonal is used for symptomatic treatment of inflammatory rheumatic diseases, degenerative and metabolic and mitigation of pain syndromes.

Indometacin is a non-steroidal antiinflammatory drug commonly used to reduce fever, pain, stiffness and swelling. It works by inhibiting the production of prostaglandins, molecules known to cause these symptoms.

Ophtagram is an antibiotic belonging to the aminoglycosides class with constant and proven efficiency on the most common germs in pathology. Ophtagram is used in topical treatment of ocular infections [4-6].

Numerous research papers have been published on pharmaceutical products [7-9]

The aim of the present study was to determine some characteristics (aspect, odor, solubility, emulsion type, water and volatile substances content, total fatty matter, saponification index, ester index) for three pharmaceutical ointments belonging to the group of non-steroidal anti-inflammatory: Diclac, Ketonal, Indometacin and one antibiotic ointment for ophthalmic use: Ophtagram. In order to achieve stability study of studied ointments, the $\mathrm{pH}$, the acidity index, the peroxide index and the iodine index were determined over a year every three months.

\section{Experimental}

2.1. Reagents and solutions 
All reagents were of analytical-reagent grade and all solutions were prepared using deionised water. The working solutions for acidity index were $\mathrm{KOH} 0.1 \mathrm{~N}$, for saponification index $\mathrm{HCl} 0.5 \mathrm{~N}$, for iodine index $\mathrm{Na}_{2} \mathrm{~S}_{2} \mathrm{O}_{3} 0.1 \mathrm{~N}$ and for peroxide index $\mathrm{Na}_{2} \mathrm{~S}_{2} \mathrm{O}_{3} 0.01 \mathrm{~N}$ solutions.

\subsection{Sample analysis}

Methods from STAS 10998-88 [10] and Romanian Farmacopeea [11] were used to determine the aspect, smell, solubility and emulsion type of the studied ointments.

$\mathrm{pH}$ values were obtained using a CONSORT C535 multimeter and for the rest of determinations we have used the titrimetric method.

For $\mathrm{pH}$ determination, we have mixed $2 \mathrm{~g}$ sample, $30 \mathrm{~cm}^{3}$ water and $5 \mathrm{~g}$ paraffin in a beaker. The mixture was heated on water bath for 30 minutes stirring occasionally. Then the mixture was cooled, the paraffin was removed and the solution was filtered using medium porosity filter paper.

For determination of water and volatile substances content we have used the equation (1):

Water and volatile substances $=\frac{m_{2}-m_{1}}{m} \cdot 100$ (1)

$(\%)$

where:

$\mathrm{m}_{2}=$ mass of phial with sample before drying $(\mathrm{g})$

$\mathrm{m}_{1}=$ mass of phial with sample after drying $(\mathrm{g})$

$\mathrm{m}=$ mass of sample for determination $(\mathrm{g})$

The equation (2) was used to determine the total fatty subsatances content in studied sample.

Total fatty substances $=\frac{m_{3}-m_{4}}{m} \cdot 100$

(\%)

where:

$\mathrm{m}_{3}=$ mass of paraffin after drying $(\mathrm{g})$

$\mathrm{m}_{4}=$ mass of paraffin that was added $(\mathrm{g})$

$\mathrm{m}=$ mass of studied sample $(\mathrm{g})$

For acidity index determination we have used the equation (3):

$$
\mathrm{I}_{\mathrm{A}}=\frac{5.61 \cdot V}{m}
$$

$(\mathrm{mgKOH} / \mathrm{g})$

where:

$I_{A}=$ acidity index
$\mathrm{V}=$ volume of $\mathrm{KOH} 0.1 \mathrm{~N}$ solution used for titration $(\mathrm{mL})$

$\mathrm{m}=$ mass of studied sample $(\mathrm{g})$

$5.61=$ number of $\mathrm{mg} \mathrm{KOH}$ coresponding to $1 \mathrm{~mL}$ $\mathrm{KOH} 0.1 \mathrm{~N}$ aqueous solution.

For determination of saponification index we have used the equation number 4 :

$$
\text { Saponification index } \mathrm{I}_{\mathrm{S}}=\frac{28.055 \cdot\left(V_{1}-V_{2}\right)}{m}
$$

$(\mathrm{mgKOH} / \mathrm{g})$

where:

28.055 = quantity of $\mathrm{KOH}(\mathrm{mg})$ coresponding to $1 \mathrm{~mL} \mathrm{HCl} 0.5 \mathrm{~N}$

$\mathrm{V}_{1}=\mathrm{HCl} 0.5 \mathrm{~N}$ volume used to titrate sample for reactiv control $(\mathrm{mL})$

$\mathrm{V}_{2}=\mathrm{HCl} 0.5 \mathrm{~N}$ volume used to titrate studied sample $(\mathrm{mL})$

$\mathrm{m}=$ mass of studied sample $(\mathrm{g})$

Ester index was obtain using the equation (5):

$(\mathrm{mgKOH} / \mathrm{g})$

$$
\mathrm{I}_{\mathrm{E}}=\mathrm{I}_{\mathrm{S}}-\mathrm{I}_{\mathrm{A}}
$$

where:

$\mathrm{I}_{\mathrm{E}}=$ ester index

$\mathrm{I}_{\mathrm{S}}=$ saponification index

$\mathrm{I}_{\mathrm{A}}=$ acidity index

For iodine index determination we have used the equation (6):

$$
\mathrm{I}_{\mathrm{I}}=\frac{\left(V_{3}-V_{4}\right) \cdot 0.01269 \cdot 100}{m}
$$

$\left(\mathrm{gI}_{2} / 100 \mathrm{~g}\right)$

where:

$\mathrm{I}_{\mathrm{I}}=$ iodine index

$\mathrm{V}_{3}=\mathrm{Na}_{2} \mathrm{~S}_{2} \mathrm{O}_{3} 0.1 \mathrm{~N}$ volume used to titrate martor sample $(\mathrm{mL})$

$\mathrm{V}_{4}=\mathrm{Na}_{2} \mathrm{~S}_{2} \mathrm{O}_{3} 0.1 \mathrm{~N}$ volume used to titrate studied sample (mL)

$\mathrm{m}=$ mass of studied sample $(\mathrm{g})$

$0.01269=$ number of grams of iod coresponding to 1 $\mathrm{mL} \mathrm{Na}_{2} \mathrm{~S}_{2} \mathrm{O}_{3} 0.1 \mathrm{~N}$ (7):

Peroxide index was obtained using the equation

$$
\text { Peroxide index }=\frac{\left(V_{5}-V_{6}\right) \cdot n \cdot 1000}{m}
$$

(mEg O2/Kg), where:

$\mathrm{V}_{5}=\mathrm{Na}_{2} \mathrm{~S}_{2} \mathrm{O}_{3} 0.01 \mathrm{~N}$ volume used to titrate studied sample $(\mathrm{mL})$ 
$\mathrm{V}_{6}=\mathrm{Na}_{2} \mathrm{~S}_{2} \mathrm{O}_{3} 0.01 \mathrm{~N}$ volume used to titrate sample for reactiv control $(\mathrm{mL})$

$\mathrm{n}=\mathrm{Na}_{2} \mathrm{~S}_{2} \mathrm{O}_{3}$ solution normality

$\mathrm{m}=$ mass of studied sample $(\mathrm{g})[12]$

\section{Results and Discussions}

To evaluate the quality of the investigated ointments the aspect, the smell and emulsion type were determined (Table 1).

Table 1. The aspect, the smell and emulsion type

\begin{tabular}{|l|l|l|c|}
\hline $\begin{array}{l}\text { The } \\
\text { ointment }\end{array}$ & The aspect & The smell & $\begin{array}{c}\text { Emulsion } \\
\text { type }\end{array}$ \\
\hline Diclac & Transparent & Pungent & O/W \\
\hline Ketonal & Transparent & Lavender & O/W \\
\hline Indometacin & Opaque & Odorless & O/W \\
\hline Ophtagram & Transparent & Odorless & W/O \\
\hline
\end{tabular}

Indometacin looks opaque because of white petrolatum from its composition and the other ointments are transparent because they are based on liquid paraffin. Diclac possess a pungent odor because of isopropyl alcohol from its composition and the smell of lavender of Ketonal is due to lavender essential oil existing in its composition.

We have also determined the solubility in some solvents of studied ointments and results are showed in Table 2.

Table 2. The solubility of the ointments

\begin{tabular}{|c|c|c|c|c|}
\hline \multirow[b]{2}{*}{$\frac{\vec{z}}{\grave{0}}$} & \multicolumn{4}{|c|}{ Ointments } \\
\hline & Diclac & Ketonal & Indometacin & Ophtagram \\
\hline 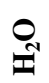 & Soluble & Soluble & Soluble & Insoluble \\
\hline$]_{0}^{0}$ & Insoluble & Insoluble & Insoluble & Soluble \\
\hline $\begin{array}{l}\text { Z } \\
\Xi \\
\underline{\Xi}\end{array}$ & Insoluble & Soluble & Insoluble & Insoluble \\
\hline 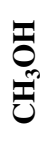 & Insoluble & Insoluble & Soluble & Soluble \\
\hline
\end{tabular}

Diclac and Ketonal got insoluble in alcohol probably because the added alcohol breaks the emulsion and precipitates the insoluble compounds.

In Fig $\mathbf{1}$ is presented the content of water and volatile substances of studied ointments.

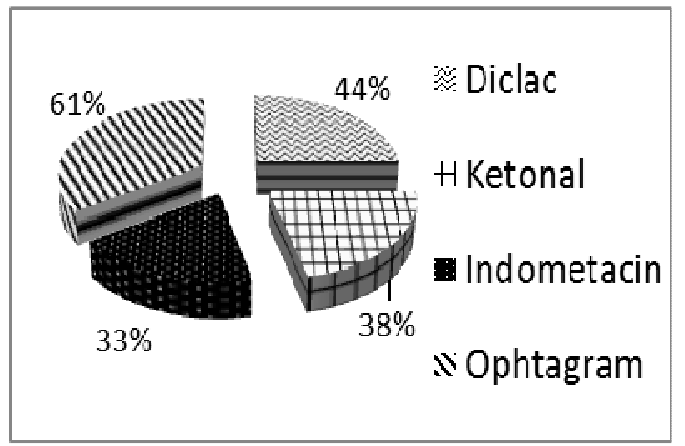

Fig. 1. The content of water and volatile substances

In Fig. 2 is presented the content of total fatty substances in studied sample.

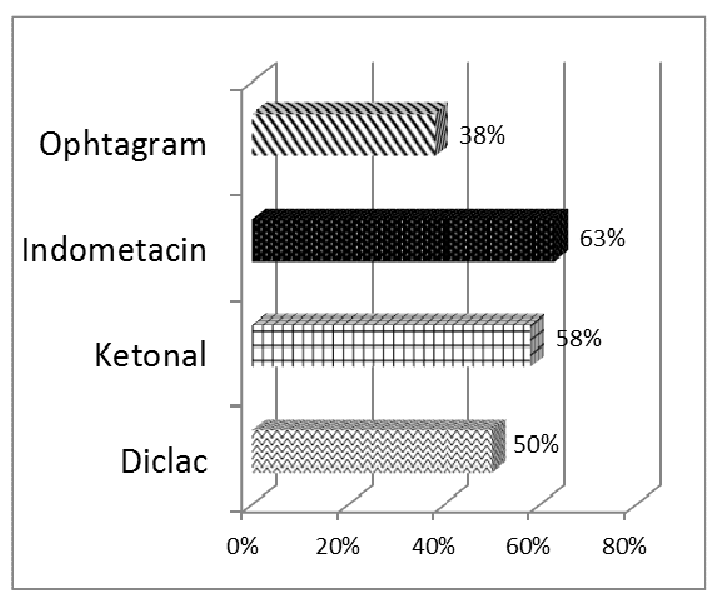

Fig. 2. The content of total fatty substances

The water and volatile substances content in the studied ointments was between 30 and $70 \%$ and the content in total fatty substances was between 20 and $85 \%$ that correspond with the literature data [13]. Indometacin had the highest precentage of total fatty substances due to white petrolatum in its composition and the lowest percentage was found in Ophtagram being the only W/O emulsion type.

In Table 3 are presented values for saponification and ester indexes. 
Saponification and ester indexes meaning the $\mathrm{KOH}$ volume used for neutralization of free fatty acids that result at sample saponification show a higher esters'content in Indometacin ointment.

Table 3. Saponification and ester indexes

\begin{tabular}{|l|c|c|}
\hline \multirow{2}{*}{ Ointment } & \multicolumn{2}{|c|}{ Indexes } \\
\cline { 2 - 3 } & Saponification & Ester \\
\hline Diclac & 134.22 & 133.33 \\
\hline Ketonal & 161.25 & 160.51 \\
\hline Indometacin & 193.08 & 192.56 \\
\hline Ophtagram & 107.51 & 106.21 \\
\hline
\end{tabular}

After performing the laboratory analysis it was revealed that all four ointments had values of ester and saponification indexes within the range 50-250 $\mathrm{mg} / \mathrm{g}$ as provided in the literature [13].

In order to achieve stability study of investigated ointments, the $\mathrm{pH}$, the acidity index, the peroxide index and the iodine index were determined over a year every three months.

In Fig. 3 are presented the variation of $\mathrm{pH}$ values for the studied ointments over a year.

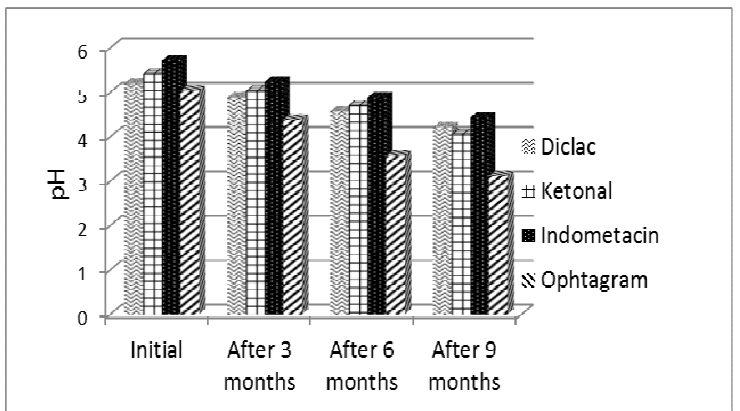

Fig. 3. The variation of $\mathrm{pH}$ values

Nine months after opening the $\mathrm{pH}$ values of the ointments are no longer within the range 4.5-6.5 provided by the literature [13]. Regarding the Ophtagram ointment $\mathrm{pH}$ values after 3 months of opening do not correspond with literature data.

In Fig. 4, 5 and 6 are presented the variations of acidity index, peroxide index and iodine index for the studied ointments over a year at each three months.

The KOH volume used for neutralization of free fatty acids from sample, wich represents the acidity index, indicates the content of fatty acids in all studied samples.

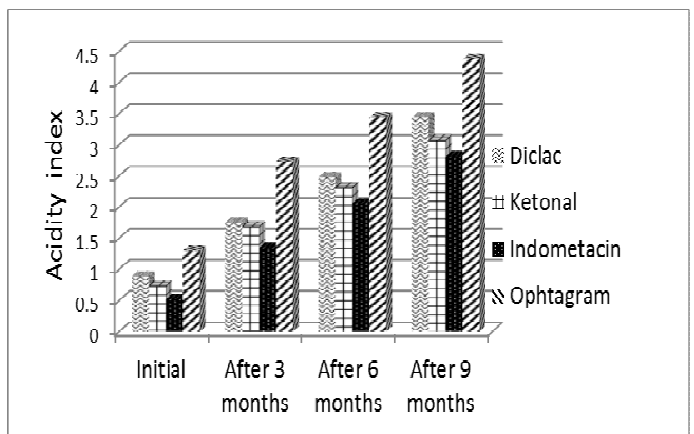

Fig. 4. The variation of acidity index

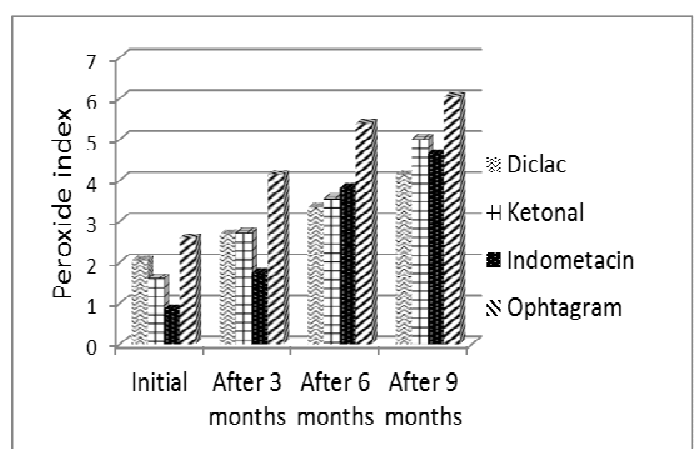

Fig. 5. The variation of peroxide index

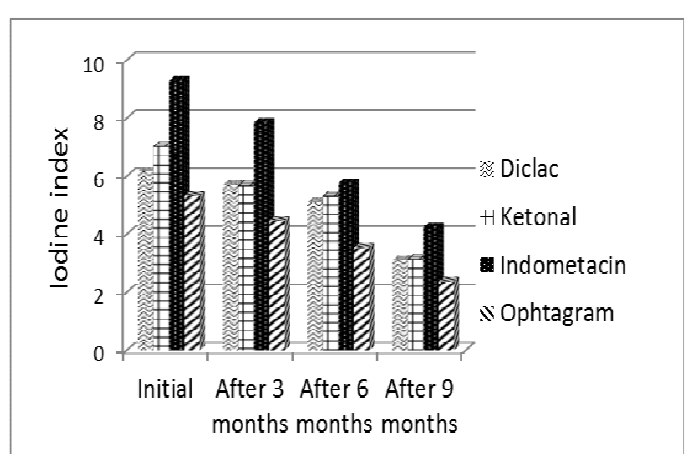

Fig. 6. The variation of iodine index

Iodine index (unsaturated hydrocarbons content) indicates a good stability at oxidation and polymerization for studied ointments.

$2.5 \mathrm{mg} / \mathrm{g}$ is the maximum limit for acidity index found in literature [13], for peroxide index is $4 \mathrm{mEq} / \mathrm{Kg}$ and iodine index must range between 5 and $15 \mathrm{mg} / \mathrm{g}$. It can be observed that 9 months after opening, the obtained values are above the maximum allowed limits. For Ophtagram, the same situation was achieved after trhee monts only. 


\section{Conclusions}

All studied ointments had a specific smell and excepting Ophtagram that was an W/O emulsion the others three were $\mathrm{O} / \mathrm{W}$ emulsions.

The content of water and volatile substances were between 30 and $70 \%$ and the content of total fatty substances were between 20 and $85 \%$ that corresponding to the literature data.

All four ointments had values of ester and saponification indexes within the range $50-250 \mathrm{mg} / \mathrm{g}$ as provided in the literature.

Nine months after opening the ointments $\mathrm{pH}$ values are no longer within the range 4.5-6.5 provided in the literature.

According to information directed on package Ophtagram is available for only one month after opening. Performing the laboratory analysis it was revealed that 3 months after opening, $\mathrm{pH}$ values, acidity, peroxide and iodine indexes do not correspond to literature data which confirms the valability of Ophtagram ointment.

\section{References}

* $\quad$ E-mail address: asoceanu@ univ-ovidius.ro

[1]. B. Baalbaki, M.D. Blanchin, and H. Fabre, Analytica Chimica Acta 463, 15 (2002),
[2]. A.L. Huidobro, A. Garcia and C. Barbas, Journal of Pharmaceutical and Biomedical Analysis, 49, 1303 (2009)

[3]. A. Panusa, G. Multari, G. Incarnato and L. Gagliardi, Journal of Pharmaceutical and Biomedical Analysis 43, 1221 (2007)

[4]. F. Wu and J. Lv, Talanta 72, 1811 (2007)

[5]. B.M. Tashtoush, J. Qasem, J.D. Williams, T.P. DeWald, E.L. Jacobson and M.K. Jacobson, Journal of Pharmaceutical and Biomedical Analysis 43, 893 (2007)

[6]. B. Tita, A. Fulias, E. Marian, and D. Tita, Rev. Chim. (Bucarest) 5, 524 (2009)

[7]. R. Hamoudova and M. Pospisilova, Journal of Pharmaceutical and Biomedical Analysis 41, 1463 (2006)

[8]. L. Havlikova, L. Matysova, L. Novakova and P. Solich, Journal of Pharmaceutical and Biomedical Analysis, 41, 671 (2006)

[9]. B. Baalbaki, E. Cheble, G. Nguema and H. Fabre, Analytica Chimica Acta 533, 121 (2005)

[10].*** STAS 10998-88, Emulsions and cosmetic creams. Methods of analysis (In Romanian)

[11].*** Romanian Farmacopeea, Ed. Medicala, Bucuresti, 1993, pp. 1-85.

[12]. A. Popovici, S. Sava, M. Ungur, E. Barocz and B. Bohn, Farmacia, 30 (2) 85 (1986)

[13]. A. Popovici, Pharmaceutical ointments (In Romanian), Ed. Medicala, Bucuresti, 1980, pp. 1-93.

Submitted: February $15^{\text {th }} 2012$

Accepted in revised form: April $3^{\text {th }} 2012$ 